\title{
MEDIA INFORMASI PARTY PLANNER BERBASIS ANDROID DENGAN AUGMENTED REALITY PADA PERSEWAAN ALAT PESTA ULUM JAYA ENTERPRISE
}

\author{
Ach. Irfan Ulum Ardianto ${ }^{1}$, Rini Agustina ${ }^{2}$ \\ Sistem Informasi, Universitas Kanjuruhan Malang ${ }^{1,2}$ \\ ardianto7705@gmail.com
}

\begin{abstract}
Abstrak. Penelitian ini fokus membahas tentang persewaan alat pesta di Ulum Jaya Enterprise menggunakan Augmented Reality berbasis Android. Aplikasi Media Informasi Party planner dibuat untuk pemesanan karena terdapat beberapa masalah yang muncul seperti kesalahan pemesanan sebelum aplikasi dibuat. Aplikasi party planner ini menampilkan barang sesuai bentuk aslinya dan membantu mengkalkulasi semua pesanan barang. Sehingga aplikasi party planner ini mendapatkan hasil yang efisien dalam menggambarkan maupun mengkalkulasi jumlah barang yang akan dipesan. Hasil perhitungan menggunakan User Acceptence Test (UAT) bahwa telah dilakukan pengujian aplikasi dan pengisian kuesioner, terdapat $91,12 \%$ responden yang menyatakan setuju jika aplikasi Media Informasi digunakan pada Ulum Jaya Enterprise.
\end{abstract}

Kata Kunci: Augmented Reality, Android, Party Planner

\section{PENDAHULUAN}

Persewaan peralatan pesta merupakan usaha yang berpeluang besar karena tingginya minat akan kebutuhan hiburan seperti perayaan pesta ulang tahun, pesta perpisahan, dan lain sebagainya. Ulum Jaya Enterprise merupakan salah satu usaha yang bergerak dibidang pesewaan peralatan pesta sejak tahun 2008 hingga sekarang. Tetapi, bisnis persewaan peralatan pesta tersebut belum memiliki pasar yang dapat membantu mempermudah proses bisnisnya dan juga promosi yang minim sehingga membuat calon konsumen kesulitan dalam mencari dan menyesuaikan tema yang cocok.

Setelah dilakukan wawancara dengan pemilik usaha persewaan peralatan pesta Ulum Jaya Enterprise, terdapat poin-poin yang dapat diambil meliputi kekurangan yang di alami pelaku bisnis di bidang persewaan peralatan pesta yaitu kuranganya alat untuk menjembatani antara konsumen dengan pelaku usaha dalam bertukar fikiran. Brosur terkadang masih dirasa kurang cukup mewakili karena beberapa konsumen masih mempertanyakan bentuk nyata barang yang akan mereka sewa.

Dengan adanya permasalahan tersebut, peneliti memberikan solusi dengan membuat sebuah Aplikasi menggunakan Augmented Reality. Diharapkan dengan adanya sistem ini dapat mengoptimalkan pelayanan pada persewaan alat pesta Ulum Jaya berdasarkan keadaan dilapangan, maka judul yang diambil dalam penyusunan Tugas Akhir ini adalah "Media Informasi Party Planner Berbasis Android Menggunakan Augmented Reality Pada Persewaan Alat Pesta Ulum Jaya Enterprise“.

\section{METODE PENELITIAN}

\section{Media Informasi}

Media informasi adalah alat grafis, fotografi atau elektronik untuk menangkap, memproses, dan kemudian menyusun kembali informasi visual.(Nurmadiah, 2016).

\section{Party Planner}


Peningkatan ini menunjukkan bahwa tingkat pendidikan menjadi lebih baik dan kemiskinan berkurang. Seiring dengan hal ini, kebutuhan masyarakat menjadi beragam, salah satunya adalah kebutuhan hiburan. Sehingga menciptakan suatu peluang usaha yaitu Event Organizer (EO) dengan jenis yang beragam. Perayaan ulang tahun merupakan salah satu hiburan yang saat ini semakin banyak dicari. Event Organizer perayaan ulang tahun pada umumnya melayani satu atau dua kalangan usia. Maka diperlukan adanya konsep baru pada EO tersebut untuk segala umur dan perayaan hari jadi (anniversary), yaitu Make-A-Wish Birthday Planner Party. Model bisnis adalah rasionalitas dari sebuah organisasi dibuat, dijalankan dan menciptakan nilai. Model bisnis terdiri dari sembilan komponen kemudian dirangkai dalam sebuah kanvas sehingga didapat gambaran dari suatu bisnis. Perancangan model bisnis Make-A-Wish Birthday Party Planner dilakukan melalui beberapa penelitian seperti wawancara kepada pelaku bisnis Adorble Party Planner, survei kepada tiga puluh calon pelanggan potensial serta diskusi pada dua puluh calon pelanggan potensial.Party Planner menyasar segmen eksekutif muda di kalangan menengah ke atas dengan usia dua puluh tahun ke atas yang tinggal di Yogyakarta. Nilai yang ditawarkan Make-A-Wish Birthday Party Planner adalah kostumisasi pembaruan ide dan konsep pesta. Komponen lain model bisnis Party Planner dijelaskan dalam model bisnis kanvas. (Lukitaningtyas et al., 2018)

\section{Multimedia Development Life Cycle (MDLC)}

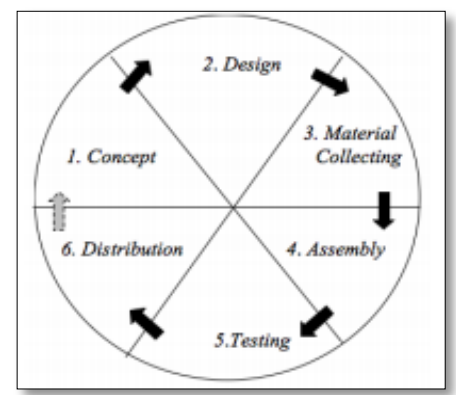

Gambar 1 Tahapan MDLC

MDLC terdapat enam tahap, tahap-tahap tersebut saling bertukar posisi. Walaupun demikian, tahap concept yaitu hal yang paling utama untuk di kerjakan .

a) Concept

Pengonsepan yaitu untuk menentukan sebuah tujuan dan penggunaan sebuah program (identifikasi). Kesimpulan dari penggunaan akhir program sangatlah berpengaruh pada suatu nuansa multimedia sebagai kilas balik dari sebuah identitas organisasi yang ingin mendapatakan informasi sampai ke pengguna. Pada tahap ini, peneliti melakukan pengonsepan untuk:

1. Menentukan tujuan metodeologi menejemen proyek serta manfaat sebuah aplikasi

2. Menentukan pengguna pada sebuah aplikasi pembelajaran metodologi proyek manajemen.

3. Menggambarkan suatu gagasan aplikasi pembelajaran Interaktif Manajemen Proyek IT yang akan dibangun.

\section{b) Design}

Desain pembuatan spesifikasi program, tampilan, model dan bahan untuk pembuatan program. Kemudian tampilan desain menu pada aplikasi dibuat menggunakan interface

\section{c) Material Collecting}

Pada tahap ini adlah mengumpulkan bahan-bahan yang dibutuhkan diantaranya gambar clp art, foto, animasi, audio, video, dan lain-lain. Bahan-bahan tersebut bisa diperoleh secara gratis ataupun memesan kepada pihak lain sesuai dengan rancangannya. Tahap ini dapat 
dikerjakan secara parallel dengan assembly, tetapi kebanyakan yang terjadi tahap ini dikerjakan secara linear dengan assembly.

\section{d) Assembly}

Assembly merupakan keseluruhan objek maupun bahan media. Membuat sebuah aplikasi berdasarkan pada desain seperti storyboard, bagan alir, atau struktur navigasi.

\section{e) Testing}

Testing merupakan sebuah tahap untuk pengujian sebuah aplikasi setelah di buat dari tahapan assembly. Kemudian untuk mengetahui hasil program maka di ajurkan untuk menjelankan aplikasiya.

\section{f) Distribution}

Distribusi merupakan suatu tahapan final dimana distribusi berperan sebagai media penyimpanan sebuah aplikasi yang telah dibuat dan apabila dalam penyimpanan tidak cukup ruang maka dilakukan kompresi.(Rifa'i et al., 2014)

\section{HASIL DAN PEMBAHASAN}

Berikut adalah tahapan penjelasan yang dilakukan dalam pengembangan media informasi party planner sesuai dengan metode $M D L C$ :

\section{Concept}

Tahap pengonsepan adalah suatu tahapan mendapatkan tujuan buat siapa pengguna aplikasi. Selain tahap pengonsepan yang juga menentukan jenis aplikasi (presentasi, interaktif dan lain-lain). Dasar peraturan dalam perencanaan juga ditentukan pada tahap pengonsepan, yaitu seperti target dan ukuran aplikasi.

Pada tahap ini mendapatkan hasil konsep diantaranya:

a. Tujuan aplikasi menghasilkan media pengenalan augmented reality mengenai konsep perancangan sebuah pesta dengan didasari produk dari pengusaha media informasi party planner dan berbasis android.

b. Manfaat dari pengenalan media informasi party planner adalah untuk membantu komunikasi antara pengusaha dengan konsumen, sehingga konsumen dapat lebih memahami konsep yang dibuat hingga mencapai kesepakan bersama.

c. Pengguna aplikasi adalah petugas lapangan dan konsumen persewaan alat pesta Ulum Jaya Enterprice.

d. Aplikasi media informasi party planner menggunakan Augmented Reality ini di buat dengan berbasis Android. (Brata \& Brata, 2018)

\section{Tabel 1 Deskripsi Konsep}

\begin{tabular}{ll}
\hline Judul & $\begin{array}{l}\text { Media Informasi Party Planner Menggunakan Augmented Reality Pada } \\
\text { Persewan Alat Pesta Ulum Jaya Enterprice }\end{array}$ \\
\hline Audiens & $:$ Konsumen yang akan memesan alat pesta \\
\hline Image & $:$ Format .jpg yang digunakan sebagai pelengkap tampilan background aplikasi \\
\hline Animasi & $:$ Berupa 3 dimensi \\
\hline Interakti-vitas & $:$ Bantuan, kembali dan tombol mulai \\
\hline
\end{tabular}

\section{Design}

Pada tahap ini design yang dibuat meliputi interface atau biasanya sering disebut tampilan. Tampilan pertama kali yang dibuat yaitu desain tampilan menu pada aplikasi android kemudian dilanjutkan dengan desain storyboard alur aplikasi sistem party planner.

Perangakat lunak yang digunakan untuk merancang interface dan storyboard. Menggambarkan scene menggunakan teks yang di buat melalui storyboard. Kemudian Untuk menggambarkan aliran scene menggunakan flowchart.(Yulianto, 2012) 
Tabel 2 Storyboard lengkap

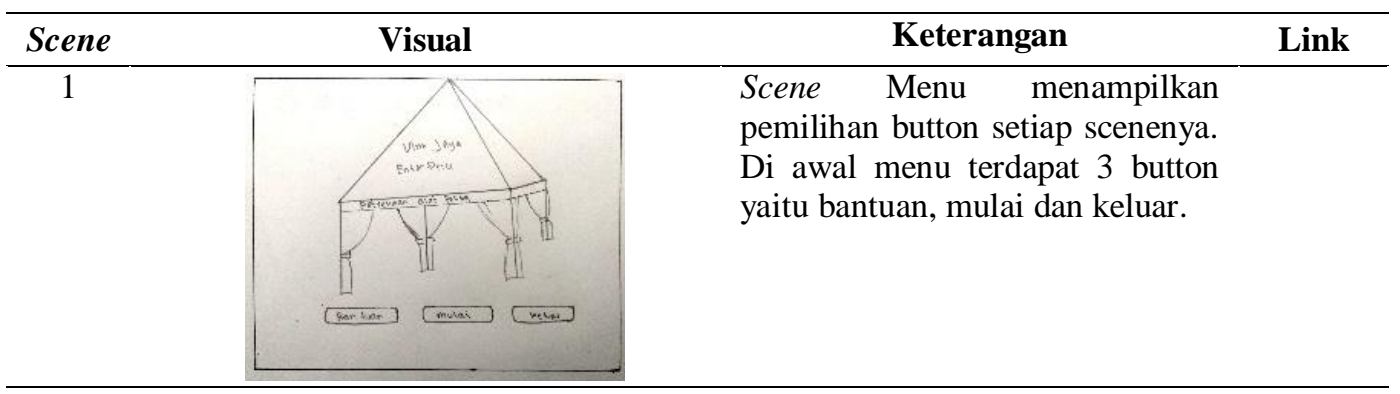

\section{Material Collecting}

Bahan yang diperlukan yaitu wawancara kepada pihak pemilik persewaan peralatan pesta, konsumen dan beberapa refrensi yang di dapat dari internet. Bahan pembuatan aplikasi yang di kumpulkan adalah gambar sebagai background maupun dokumen dalam media informasi party planner. Kemudian juga terdapat buku album Ulum Jaya Enterprise sebagai acuan pengambilan data.

Aplikasi ini membutuhkan perangkat keras dan lunak. Perangkat keras yang di gunakan PC dengan spesifikasi: Processor Amd Quard Core, dan Memory 6GB. Perangkat lunak yang di butuhkan adalah Windows 7 Operating System, sedangkan untuk membuat, mengelola aplikasi menggunakan Blender dan Unity. (Mustika et al., 2018)

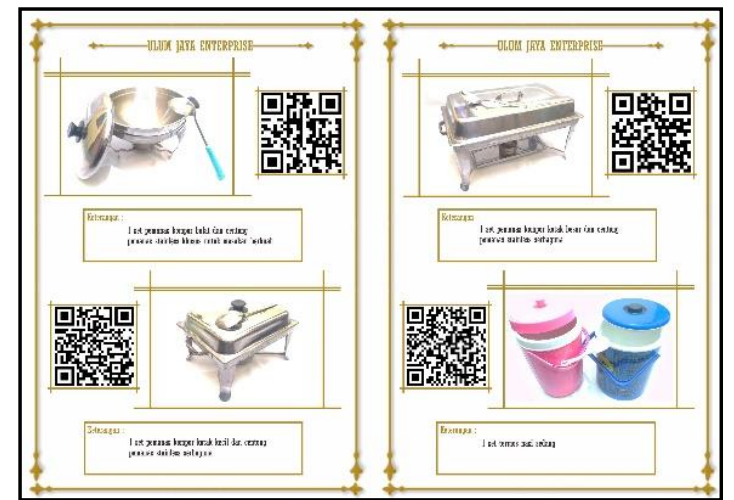

Gambar 2 Buku Album Ulum Jaya Enterprise

\section{Assembly}

Berdasarkan storyboard yang telah dibuat maka pada tahapan ini pembuatan animasi menggunakan Software Blender 3D, untuk database marker menggunakan vuforia sdk, untuk implementasi augmented reality serta tampilan pada aplikasinya mengunakan Unity $3 D$ dimana untuk alur aplikasi media informasi party planner mengacu pada flowchart alur aplikasi dan untuk penilaian terhadap konsumen menggunakan User Acceptance Test (UAT).

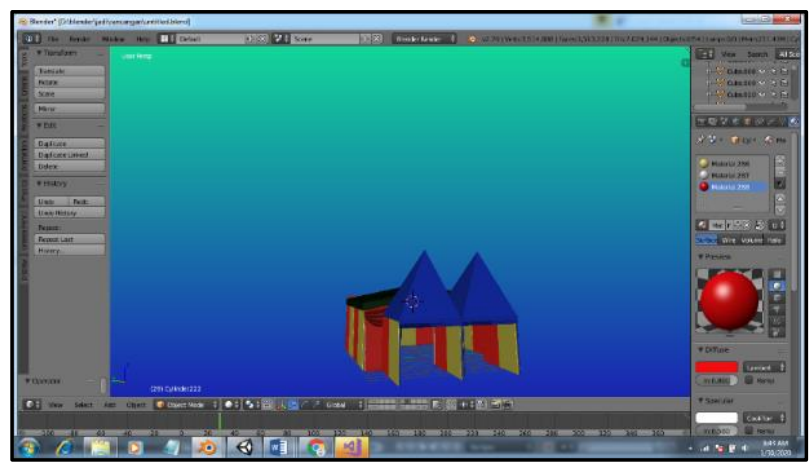

Gambar 3 Modelling tenda Ulum Jaya Enterprise 


\section{Testing}

Testing merupakan sebuah tahapan untuk pengujian sebuah aplikasi setelah dibuat dari tahap assembly. Kemudian untuk mengetahui hasil program maka di ajurkan untuk menjalankan aplikasiya dan pengujian menggunakan uji Black Box gagal dan berhasil. (Rosa \& Salahuddin(2014:50), 2016)

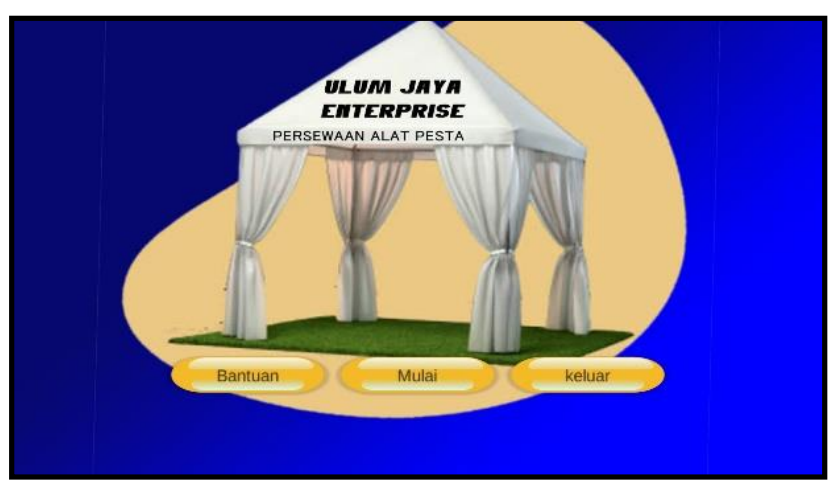

Gambar 4 Menu apk

Tabel 3 Pengujian Menu Utama Aplikasi AR Party Planner

\begin{tabular}{cccc}
\hline Tujuan Uji & Melakukan Uji Coba Pada & Menu Utama Aplikasi AR Party Planner \\
\hline Desain Interface & Hasil Yang Diharapkan & Hasil Pengamatan & Keterangan \\
\hline $\begin{array}{c}\text { Tampilan Menu Utama } \\
\text { aplikasi Party palanner }\end{array}$ & $\begin{array}{c}\text { Bisa menampilkan menu } \\
\text { utama aplikasi Party } \\
\text { palanner }\end{array}$ & $\begin{array}{c}\text { Menu utama muncul atau } \\
\text { tampil }\end{array}$ & Berhasil \\
& & & \\
\hline
\end{tabular}

\section{Distribution}

Aplikasi media informasi pengenalan produk peralatan pesta yang akan dibuat menggunakan Blender 3D, Vuforia sdk dan Unity, dimana file-file proyek disimpan dalam bentuk *.blend (Blender 3D dokumen), project unity (vuforia sdk) dan aset (Unity dokumen). Jika aplikasi telah selesai dibuat, kemudian di export menjadi file *apk, sehingga aplikasi tersebut bisa dijalankan diperangkat smartphone berbasis android. (Qadriyanto \& Bahri, 2018)

\section{Pengembangan Produk Awal}

Dalam mengembangkan aplikasi membutuhkan alur yang menggambarkan tahap awal hingga akhir. Berikut merupakan flowchart aplikasi Media Informasi Party Planner:

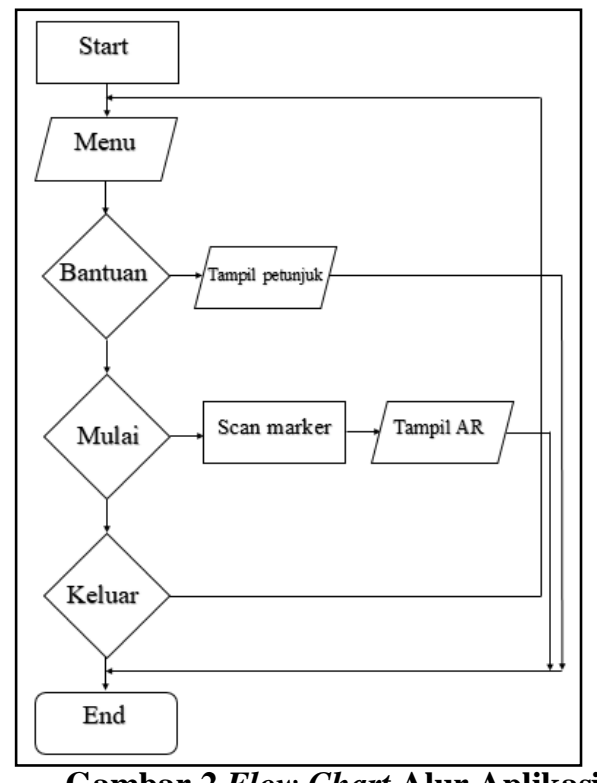

Gambar 2 Flow Chart Alur Aplikasi 


\section{Uji Coba Produk}

Dalam mengembangkan produk multimedia, diperlukan uji coba media dengan maksud apakah hasil produk yang telah dibuat layak untuk digunakan. Kemudin data yang di dapat selanjutnya di analisis dan diperbaiki atau disempurnakan agar menghasikan kualitas produk yang lebih baik.

\section{Jenis Data}

Kuantitatif adalah metode penulisan yang digunakan oleh penulis, metode penelitian yang menjelaskan tentang riset bersifat perhitungan. Penelitian kuantitatif digunakan untuk mengukur data dan statistik objektif yang berasal dari data sampel.

\section{Instrumen Pengumpulan Data}

Peneliti menggunakan kuisioner sebagai instrumen pengumpulan data. Kemudian kuisioner instrumen pengumpulan data dilanjutkan dengan pemberian skor sebagai berikut :

Tabel 4 Skor Kuisioner

\begin{tabular}{ccc}
\multicolumn{3}{c}{ Tabel 4 Skor Kuisioner } \\
\hline A & Sangat Setuju & Diberi skor 5 \\
\hline B & Setuju & Diberi skor 4 \\
\hline C & netral & Diberi skor 3 \\
\hline D & Cukup Setuju & Diberi skor 2 \\
\hline E & Tidak Setuju & Diberi skor 1 \\
\hline
\end{tabular}

\section{Teknik Analisis Data}

Teknis analisis data yang menentukan dari suatu penelitian, karena digunakan agar bisa menyimpulkan hasil dari penelitian. Teknik dan prosedur yang digunakan dalam analisis dikemukakan pada bagian ini dan tentunya disertai alasan berdasarkan jenis dan komponen produk yang dikembangkan. Data yang di analisis dalam penelitian ini berupa data kuantitatif, berikut tahapannya :

a. Perencanaan

Dalam kegiatan ini tahapan yang dilakukan adalah :

1. Merancang sampel penelitian yang dijadikan kelas.

2. Instrumen yang terkait dengan penelitian.

b. Pelaksanaan

Dalam kegiatan ini tahapan yang dilakukan adalah :

1. Pembelajaran terhadap sampel penelitian.

2. Melakukan analisis, uji coba dan menetapkan instumen-instrumen yang digunakan dalam penelitian ini.

c. Evaluasi

Menganalisis dan mengolah data hasul penelitian dengan menggunkan metode yang sudah di tentukan.

d. Penyusunan Laporan

Hasil dari penelitian yang telah dilakukan selanjutnya disusun kedalam bentuk laporan.

\section{KESIMPULAN}

Berdasarkan hasil penelitian, perancangan, pembuatan dan uji coba aplikasi yang telah diakukan menggunakan User Acceptance Test (UAT) mendapat total nilai rata-rata 91,12\%. Maka dapat ditarik kesimpulan bahwa aplikasi Media Informasi Party Planner Berbasis Android Menggunakan Augmented Reality dapat diterima, meningkatkan pemahaman dan ketertarikan konsumen terhadap pemesanan persewaan alat pesta Ulum Jaya Enterprice.

\section{SARAN}

Berikut merupakan saran untuk pengembangan terhadap aplikasi Party Planner Berbasis Android Degan Augmented Reality Pada Persewaan Alat Pesta Ulum Jaya Enterprise, yaitu: a. Pengaturan pembaharuan harga melalui aplikasi. 
b. Bisa mencetak Nota.

c. Objek bisa lebih detail lagi dari segi bentuk maupun pewarnaan.

d. Objek bisa degerakan maupun di perbesar maupun dikecilkan sesuai kemauan user.

\section{DAFTAR RUJUKAN}

Auditia Setiobudi, Nurul Indarti, Sivilokonom. Cand. Merc., Ph D.(2016). Model Bisnis Make-A-Wish Birthday Party Planner (Online). Tersedia di (http://etd.repository.ugm.ac.id/home/detail_pencarian/95550), diakses 6 Februari 2020.

Agustino ,Dedi Panji. 2018. Perancangan Augmented Reality Convention Center. STIMIK STIKOM Bali.

Brata, K. C., \& Brata, A. H. (2018). Pengembangan Aplikasi Mobile Augmented Reality untuk Mendukung Pengenalan Koleksi Museum. Jurnal Teknologi Informasi Dan Ilmu Komputer. https://doi.org/10.25126/jtiik.201853798

Lukitaningtyas, I., Andreswari, R., \& Al-anshary, F. M. (2018). RANCANG BANGUN EMARKETPLACE “ DYLAND " BAGI PENYEDIA JASA EVENT ORGANIZER-PARTY PLANNER MENGGUNAKAN METODE ITERATIVE INCREMENTAL ( MODUL TRANSAKSI ). EProceedings of Engineering.

Mustika, M., Sugara, E. P. A., \& Pratiwi, M. (2018). Pengembangan Media Pembelajaran Interaktif dengan Menggunakan Metode Multimedia Development Life Cycle. Jurnal Online Informatika. https://doi.org/10.15575/join.v2i2.139

Nurmadiah, N. (2016). MEDIA PENDIDIKAN. Al-Afkar : Jurnal Keislaman \& Peradaban. https://doi.org/10.28944/afkar.v5i1.109

Qadriyanto, M., \& Bahri, S. (2018). Rancang Bangun Aplikasi Visualisasi 3d Furniture Interior Rumah Menggunakan Augmented Reality Dengan Metode Markerless Berbasis Android. Jurnal Coding.

Rifa'i, M., Listyorini, T., \& Latubessy, A. (2014). PENERAPAN TEKNOLOGI AUGMENTED REALITY PADA APLIKASI KATALOG RUMAH BERBASIS ANDROID. Prosiding SNATIF Ke-1.

Yulianto, N. (2012). PEMBUATAN GAME 3 DIMENSI LOST IN THE JUNGLE DENGAN MENGGUNAKAN UNITY 3D GAME ENGINE. 